\title{
A Simple in Syringe Low Density Solvent-Dispersive Liquid Liquid Microextraction for Enrichment of Some Metal Ions Prior to Their Determination by High Performance Liquid Chromatography in Food Samples
}

\author{
Melasinee Laosuwan, Siriboon Mukdasai and Supalax Srijaranai * \\ Materials Chemistry Research Center, Department of Chemistry and Center of Excellence for Innovation in \\ Chemistry, Faculty of Science, Khon Kaen University, Khon Kaen 40002, Thailand; \\ melasineemela@gmail.com (M.L.); sirimuk@kku.ac.th (S.M.) \\ * Correspondence: supalax@kku.ac.th; Tel.: +66-43-202222-41 (ext. 12243); Fax: +66-43-202373
}

Received: 21 December 2019; Accepted: 23 January 2020; Published: 28 January 2020

check for updates

\begin{abstract}
A simple and highly sensitive method is developed for the simultaneous determination of $\mathrm{Ni}^{2+}, \mathrm{Cr}_{2} \mathrm{O}_{7}{ }^{2-}, \mathrm{Co}^{2+}$, and $\mathrm{Hg}^{2+}$ by using in syringe low density solvent-dispersive liquid liquid microextraction (ISLD-DLLME), followed by high performance liquid chromatography with a UV detector. The four metal ions were derivatized with pyrrolidine dithiocarbamate (PDC) based on complexation before their enrichment by ISLD-DLLME in which 1-octanol and methanol were used as the extraction solvent and the dispersive solvent, respectively. The extraction was performed in a commercially available syringe under vortex agitation. Phase separation was achieved without centrifugation, and the extraction phase was easily collected by moving the syringe plunger. Parameters affecting the extraction efficiency were studied and optimized. Under the optimum conditions, the four metal-PDC complexes were detected within $18 \mathrm{~min}$, and ISLD-DLLME could increase the detection sensitivity in the range of 64-230 times compared to the direct HPLC analysis. The obtained limits of detection (LODs) were found to be in the range of $0.011-2.0 \mu \mathrm{g} \mathrm{L}^{-1}$. The applicability of the method is demonstrated for freshwater fish, shrimp, and shellfish samples. In addition, the results are in good agreement with those obtained by inductively-coupled plasma-optical emission spectrometry (ICP-OES).
\end{abstract}

Keywords: liquid phase microextraction; in-syringe microextraction; metal complex; pyrrolidine dithiocarbamate; simultaneous analysis

\section{Introduction}

The determination of metal ions is still an importance issue in many fields such as the environment and food sectors. [1]. The instrumental methods that are widely used for the determination of metal ions are based on atomic spectrophotometry like as atomic absorption spectrometry (AAS) [2,3], inductively-coupled plasma-optical emission spectrometry (ICP-OES) [4], and inductively-coupled plasma-mass spectrometry (ICP-MS) [5]. Recently, optical sensors have been employed for the detection of metal ions [6,7]. Though these methods are sensitive, highly precise and accurate, they are recognized as a "single-element" analytical technique. Multi-elemental analysis can be achieved with either ICP-OES or ICP-MS, but the instrument and operating costs are expensive. Another instrumental technique for the simultaneous analysis of metals is high performance liquid chromatography (HPLC). Various modes of HPLC have been successfully employed for 
the simultaneous analysis of metal ions such as ion exchange and the reversed phase. In addition, a number of hyphenated techniques for the HPLC analysis of metal ions, such as ion chromatography coupled with hydride generation-inductively-coupled plasma atomic emission spectrometry [8], ion chromatography [9] and high performance liquid chromatography coupled to inductively-coupled plasma mass spectrometry [10] have been reported. Most of chromatographic analysis of metal ions is performed after their pre-derivatization by complex formation with appropriate chelating agents. The complexation of metal ions provides not only selectivity that arises from the behavior of individual complexes but also sensitivity for absorption detection from the high absorption coefficient of metal complexes.

The metal ions of interest in this study are $\mathrm{Ni}^{2+}, \mathrm{Cr}_{2} \mathrm{O}_{7}{ }^{2-}, \mathrm{Co}^{2+}$, and $\mathrm{Hg}^{2+} \cdot \mathrm{Ni}^{2+}$ and $\mathrm{Co}^{2+}$, at trace concentrations, are essential for the human diet in order to maintain normal physiological functions [11]. At high concentrations, $\mathrm{Ni}^{2+}$ is highly toxic to the cardiovascular system and irritates the skin [12], while large amount of $\mathrm{Co}^{2+}$ affects breathing, asthma, pneumonia, wheezing, and skin rashes [13]. The level of toxicity of metals is dependent on their form (e.g., inorganic and organic) and oxidation states. For instance, $\mathrm{Cr}^{6+}$ is suspected to be a carcinogen and mutagenic compound [14], while $\mathrm{Cr}^{3+}$ is an essential trace element [15]. Inorganic mercury $\left(\mathrm{Hg}^{2+}\right)$ is harmful to the tissue systems of humans [15]. These metal ions have been employed in various manufacturing processes such as those for paper, paint, plastic, electrochemical products, and pharmaceuticals, so they can contaminate the environment and the food chain [1]. To ensure food safety, regulations have been established by various authorized organizations. The maximum residue limit (MRL) of chromium in fish and shellfish has been regulated to be $2.0 \mathrm{mg} \mathrm{kg}^{-1}$ by United States Department of Agriculture (USDA) Foreign Agricultural Service [16]. The recommended MRL for $\mathrm{Hg}^{2+}$ by the European Union (EU) is in the range of $0.5-1.0 \mathrm{mg} \mathrm{kg}^{-1}$ fresh weight for fish muscle and other fishery products [17], while the dietary reference intake (DRI) of $\mathrm{Ni}^{2+}$ is regulated as less than $0.2 \mathrm{mg}$ per day in food by the World Health Organization (WHO) [18]. Furthermore, the DRI allowance of $\mathrm{Co}^{2+}$ from food is estimated to be 5-40 $\mu \mathrm{g}$ per day by the Environmental Protection Agency (EPA) [19].

The determination of metal ions at trace levels can usually be achieved by an additional step that is known as the preconcentration method before the instrumental analysis. Various preconcentration techniques have been developed for the analysis of metal ions in order to increase sensitivity of the detection. Nowadays, the miniaturized approach of a classical liquid-liquid extraction (LLE), namely liquid phase microextraction (LPME), has gained extensive attention. Among various techniques of LPME, dispersive liquid-liquid microextraction (DLLME) has been accepted as the most popular technique because of its simplicity and rapidity. DLLME is composed of ternary solvents, including an aqueous solution containing the target analytes being extracted, an organic solvent as the extraction solvent, and a water-miscible organic solvent as the dispersive solvent $[20,21]$. The extraction occurs immediately after a rapid injection of a mixture of extraction and dispersive solvents into the aqueous phase, after which a cloudy phase is usually observed. Afterward, phase separation is then achieved by centrifugation, and the enriched analytes that are usually present in the sedimented phase are subsequently determined by appropriate techniques. There are a numbers of research works on DLLME for the determination of metal ions [22-25].

Likewise, for LLE, the extraction solvent is a key parameter for DLLME. In the first period of DLLME, solvents having higher densities than water, such as chlorinated solvents including chlorobenzene, carbon tetrachloride, and tetrachloroethylene, are used as the extraction solvents. However, these solvents are toxic [26]. Recently, to fulfill the green analytical concept, the solvents with lower densities than water, which are considered to be less toxic than those with higher densities, are used as the extraction solvent. DLLME, which employs a low-density extraction solvent, still has a problem in the collection of the extraction phase that presents as a floating drop at the top of the aqueous phase after centrifugation [26-28]. To overcome this problem, specially designed extraction vessels are used. Most of the specifically-designed extraction devices are either long-neck or narrow-neck 
vessels $[20,29,30]$. Thus far, the simplest reported extraction devices are syringes and syringes with pipet tip on top [31-34].

The aim of this study was to develop a simple and highly sensitive method for the simultaneous determination of $\mathrm{Ni}^{2+}, \mathrm{Cr}_{2} \mathrm{O}_{7}{ }^{2-}, \mathrm{Co}^{2+}$, and $\mathrm{Hg}^{2+}$ by HPLC. The method consists of the pre-derivatization of metal ions by complex formation with pyrrolidine dithiocarbamate (PDC), the preconcentration of the metal-PDC complexes by in syringe low density solvent-dispersive liquidliquid microextraction (ISLD-DLLME), and, finally, the determination of the enriched metal-PDC complexes by HPLC equipped with UV detector. The proposed method (ISLD-DLLME) followed by HPLC was then applied for the analysis of the metal ions in freshwater fish, shrimp and shellfish samples. In addition, ICP-OES was employed for comparison.

\section{Results and Discussion}

PDC was chosen as the chelating agent to form complexes with the studied metal ions because of its high complexation capability with a number of metal ions and the fact that it provides high molar absorptivity complexes $[35,36]$. There are a number of reports on the determination of metal ions based on PDC-complexes by using various instrumental methods such as UV-Vis spectrophotometry [37], flame atomic absorption spectrometry (FAAS) [2], electrothermal atomic absorption spectrometry (ETAAS) [3], ICP-OES [4], ICP-MS [5] and HPLC [38,39]. In addition, PDC has been used to lower analytical limits of FAAS [40].

Generally, the anion of pyrrolidine dithiocarbamate forms neutral complexes with most metal ions, and it has been documented that the analysis of metal-PDC complexes can be achieved by extracting the complexes into organic solvents before their instrumental analysis [35,39,41,42]. In this study, ISLD-DLLME was developed for extraction of metal-PDC complexes prior to their analysis by reversed phase HPLC.

\subsection{Separation of Metal-PDC Complexes by HPLC}

The optimum mobile phase was a mixture of acetonitrile (ACN) and water at a ratio of 70/30 $(\mathrm{v} / \mathrm{v})$. Under optimum conditions, the separation of the studied metal-PDC complexes was achieved within 18 min with the order of elution of Ni(II)-PDC (11.5 min), Cr(VI)-PDC (12.9 min), Hg(II)-PDC (16.0 $\mathrm{min})$, and Co(II)-PDC (17.6 $\mathrm{min})$, and the excess PDC was eluted at $7.5 \mathrm{~min}$.

\subsection{In Syringe Low Density Solvent-Dispersive Liquid Liquid Microextraction (ISLD-DLLME)}

The experimental parameters that influenced the extraction efficiency were optimized, and the results of this optimization are presented in Sections 2.2.1-2.2.5. The average values of the peak area including the standard deviation (from triplicate experiments) were plotted either as bar or line graphs.

\subsubsection{The Effect of $\mathrm{pH}$}

The $\mathrm{pH}$ of an aqueous solution has a key role in metal complex formation and extraction efficiency. The effect of $\mathrm{pH}$ was studied in the range of 3.0-9.0 by using a phosphate buffer. The results (Figure S1) revealed that the $\mathrm{pH}$ had a different effect for each metal ion. The $\mathrm{pH}$ slightly affected the extraction of the PDC complexes of $\mathrm{Co}^{2+}$ and $\mathrm{Hg}^{2+}$. The extraction efficiency of $\mathrm{Ni}(\mathrm{II})-\mathrm{PDC}$ was strongly influenced by $\mathrm{pH}$, as the peak area increased with the increasing of $\mathrm{pH}$ from 3.0 to 5.0; after that, the efficiency dramatically decreased from $\mathrm{pH} 7$ to 9 . While, the extraction of $\mathrm{Cr}(\mathrm{VI})-\mathrm{PDC}$ was significantly decreased at $\mathrm{pH}$ levels higher than 5.0. Form the results, $\mathrm{pH} 5.0$ was chosen for further studies because it provided the highest efficiency for all the studied metal ions.

\subsubsection{Effect of Types and Volume of the Extraction Solvent}

The type of extraction solvent is one of the most important parameters that influences extraction efficiency. The general characteristics for a good extraction solvent including (i) a high affinity to the 
target analytes, (ii) compatibility with HPLC separation, and (iii) a low solubility in water [20,26,43]. In addition, to be environmentally benign, the extraction solvent should have a lower density than water. The studied solvents were those that having densities lower than water, including 1-octanol, 1-undecanol, and 1-dodecanol, which their logs Kow are 3.21, 4.83 and 5.36, respectively [44]. The results (Figure 1a) showed that the most polar solvent, 1-octanol, provided the highest extraction efficiency.

The extraction solvent volume directly affected the extraction efficiency. A sufficient extraction solvent is required for effective extraction. To investigate the effect of the extraction solvent, different volumes of 1-octanol $(50,75,100$ and $125 \mu \mathrm{L})$ were studied. The results shown in Figure $1 \mathrm{~b}$ indicate that the peak area continuously decreased with the increasing volume of 1-octanol because a large volume of extraction solvent resulted in a dilution of the analytes in the extraction phase [20]. However, a volume of less than $50 \mu \mathrm{L}$ could not be studied due to the resulting poor phase separation, so the collection of the extraction phase was difficult. Therefore, $50 \mu \mathrm{L}$ of 1-octanol was chosen as the optimum extraction solvent volume.
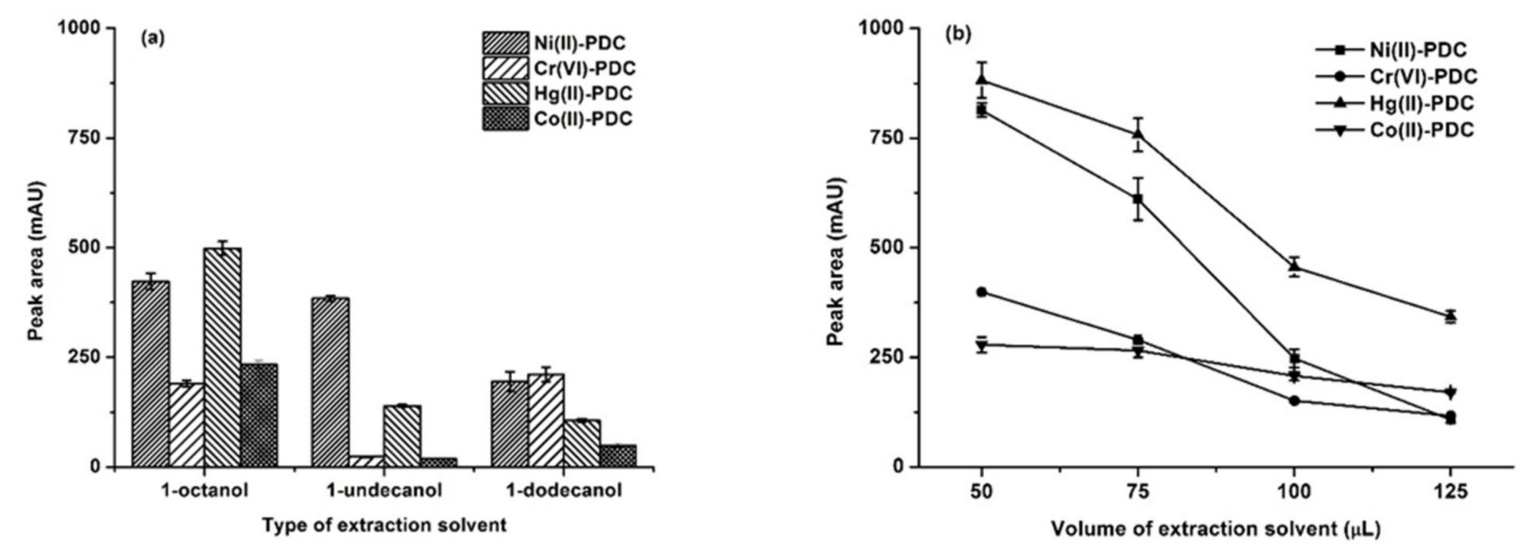

Figure 1. (a) The effect of the types of extraction solvent. Extraction conditions: $0.1 \mathrm{~mol} \mathrm{~L}^{-1}$ phosphate buffer at $\mathrm{pH} 5,75 \mu \mathrm{L}$ of extraction solvent, $300 \mu \mathrm{L}$ of acetonitrile, and $20 \mathrm{~s}$ of vortex. (b) The effect of the extraction solvent volume. Extraction conditions: $0.1 \mathrm{~mol} \mathrm{~L}^{-1}$ phosphate buffer at $\mathrm{pH} 5,50-125 \mu \mathrm{L}$ of 1-octanol, $250 \mu \mathrm{L}$ of methanol, and $20 \mathrm{~s}$ of vortex.

\subsubsection{Effect of Types and Volume of the Dispersive Solvent}

The role of the disperser solvent not only assists in the formation of tiny drops of the extraction solvent but also facilitate its dispersion. The following properties should be considered for the disperser solvent: (i) a high water solubility (ii), miscibility in the extraction solvent, and (iii) a small surface tension [28,43]. In this study, the most widely used dispersive solvents, such as methanol, acetonitrile, acetone and ethyl acetate, were investigated. The results (Figure 2a) showed that methanol gave the highest peak area. Therefore, methanol was selected as the optimal dispersive solvent.

The volumes of the dispersive solvent directly affect the cloudy phenomenon in DLLME [41,43]. The cloudy phenomenon indicates the emulsion of the fine droplets of the extraction solvent. A complete emulsion is therefore not formed if an insufficient dispersive solvent volume is used, thus leading to a decrease in the efficiency extraction. On the other hand, a large volume of dispersive solvent results in increasing volume of extraction solvent, thus decreasing the extraction efficiency. Different volumes of methanol (100, 150, 200, 250 and $300 \mu \mathrm{L})$ were investigated. As can be seen from the results in Figure $2 b$, the peak area increased and reached a maximum at $250 \mu \mathrm{L}$ of methanol before decreasing slightly at $300 \mu \mathrm{L}$. Therefore, $250 \mu \mathrm{L}$ of methanol was chosen. 

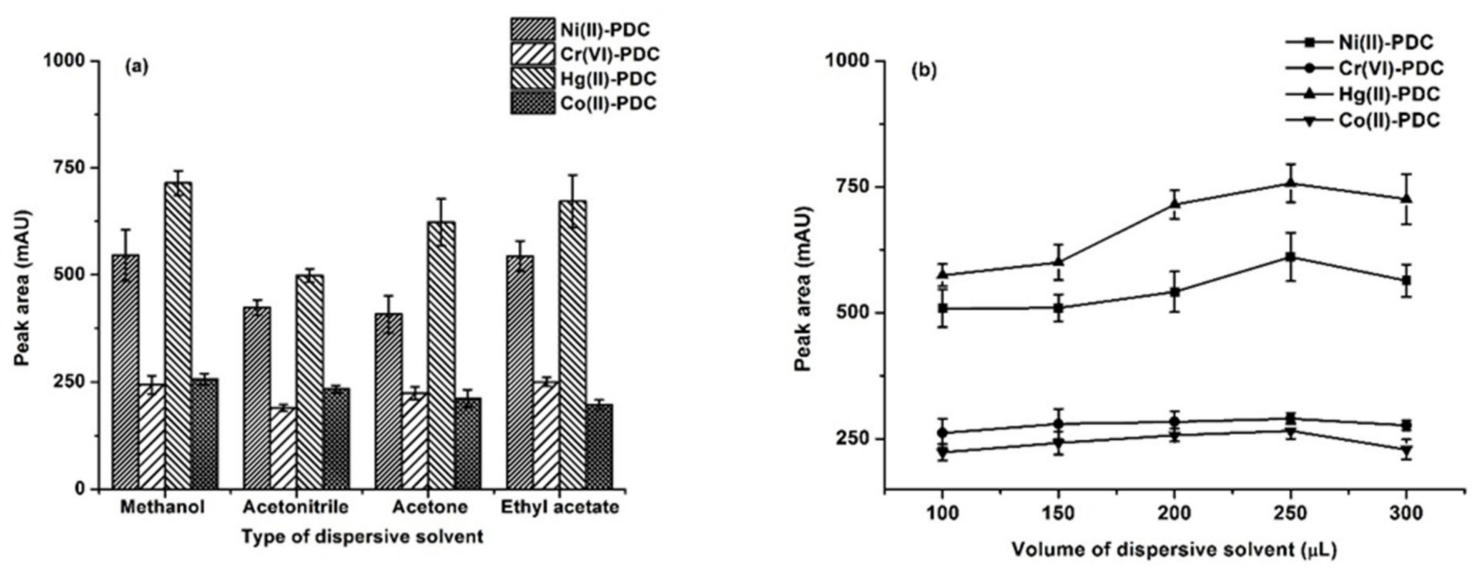

Figure 2. (a) The effect of the dispersive solvent type. Extraction conditions: $0.1 \mathrm{~mol} \mathrm{~L}^{-1}$ phosphate buffer at $\mathrm{pH} 5,75 \mu \mathrm{L}$ of 1-octanol, $300 \mu \mathrm{L}$ of dispersive solvent, and $20 \mathrm{~s}$ of vortex. (b) The effect of the dispersive solvent volume. Extraction conditions: $0.1 \mathrm{~mol} \mathrm{~L}^{-1}$ phosphate buffer at $\mathrm{pH} 5,75 \mu \mathrm{L}$ of 1-octanol, $100-300 \mu \mathrm{L}$ of methanol, and $20 \mathrm{~s}$ of vortex.

\subsubsection{Effect of Salt Addition}

For DLLME, the addition of salt increases the extraction efficiency by decreasing the solubility of the analytes in the aqueous solution and enhancing the partitioning of analytes into the organic phase as a result of the salting out effect [31]. In this study, $1 \%(w / v)$ of various salts including $\mathrm{NaCl}$, $\mathrm{Na}_{2} \mathrm{SO}_{4}$ and $\mathrm{Na}_{2} \mathrm{CO}_{3}$, were added to evaluate the effect of salt on extraction efficiency. The results are depicted in Figure 3, revealing that the peak area of all analytes decreased with the addition of salts compared to those without the salt addition. This may have been due to the fact that the addition of salts increases the ionic strength and viscosity of the aqueous phase, resulting in the decreasing of mass transfer [44]. Therefore, subsequent experiments were carried out without salt addition.

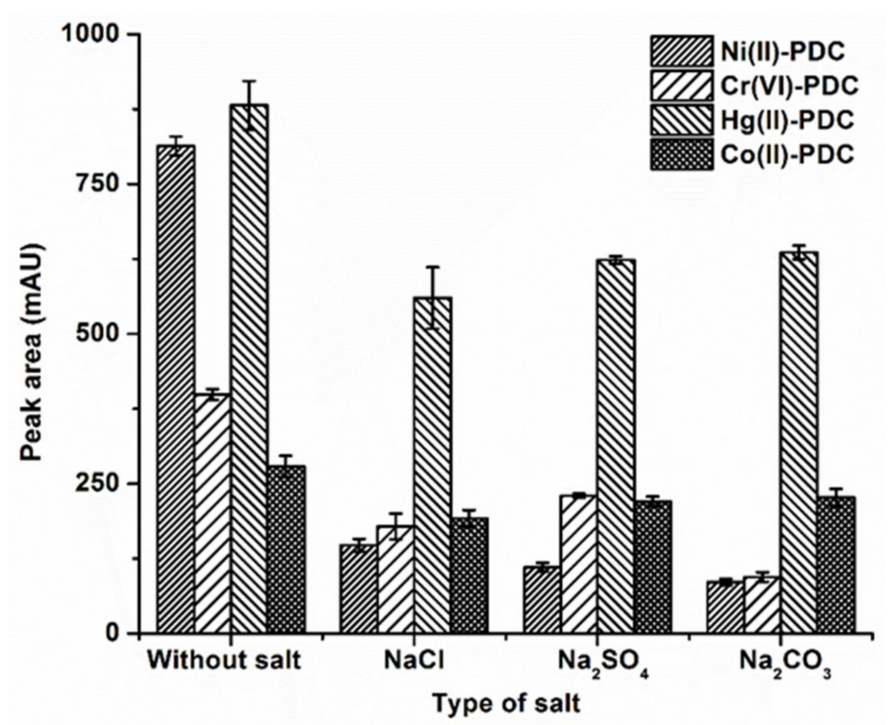

Figure 3. The effect of type of salt on the extraction efficiency. Extraction conditions: $0.1 \mathrm{~mol} \mathrm{~L}^{-1}$ phosphate buffer at $\mathrm{pH} 5,50 \mu \mathrm{L}$ of 1 -octanol, $250 \mu \mathrm{L}$ of methanol, $20 \mathrm{~s}$ of vortex, and $1 \% w / v$ salt.

\subsubsection{Effect of Vortex Time}

Extraction time is another important parameter. The extraction time is defined as the vortex time after the injection of a mixture of the extraction solvent and the dispersive solvent into the aqueous solution. Additionally, with the increased mixing of all reagents, a vortex can enhance the dispersion of the extraction solvent into an aqueous solution. The effect of vortex time was investigated in the range 
of 0-100 s. The maximum peak area was obtained at a vortex time of $20 \mathrm{~s}$ (Figure S2); after that, the peak area remained almost constant for the PDC complexes except for the Hg(II) PDC. Consequently, $20 \mathrm{~s}$ was used as the optimal extraction time.

\subsubsection{Analytical Features}

The analytical characteristics of the proposed ISLD-DLLME were investigated by using the optimum conditions as follows: 1-octanol $(50 \mu \mathrm{L})$ was used as the extraction solvent, and methanol $(250 \mu \mathrm{L})$ was used as the disperser solvent-these were vortexed for $20 \mathrm{~s}$. The ISLD-DLLME could significantly enhance the sensitivity for the determination of metal ions, as can be clearly seen in Figure 4. The analytical performance of ISLD-DLLME coupled to HPLC was compared to the direct HPLC analysis, and the results of this are summarized in Table 1 . The linearity was deduced from the calibration curve of five different concentrations of each metal ions in the ranges of $0.050-5.0 \mu \mathrm{g} \mathrm{L}^{-1}$ for $\mathrm{Ni}^{2+}, \mathrm{Cr}_{2} \mathrm{O}_{7}{ }^{2-}, \mathrm{Co}^{2+}$, and 5.0-200 $\mathrm{gg} \mathrm{L}^{-1}$ for $\mathrm{Hg}^{2+}$. Each metal ion exhibited a good linearity with correlation coefficients $\left(\mathrm{R}^{2}\right)$ ranging from 0.9949 to 0.9979 . The limit of detection (LOD) and the limit of quantitation (LOQ) were calculated based on the signal to noise $(\mathrm{S} / \mathrm{N})$ ratios of 3 and 10, respectively. The LODs were 0.011-0.014 $\mathrm{gg} \mathrm{L}^{-1}$ for $\mathrm{Ni}^{2+}, \mathrm{Cr}_{2} \mathrm{O}_{7}{ }^{2-}$, and $\mathrm{Co}^{2+}$, and the LOD was $2.0 \mu \mathrm{g} \mathrm{L}^{-1} \mathrm{for} \mathrm{Hg}^{2+}$. The LOQs were $0.047-0.050 \mu \mathrm{g} \mathrm{L}^{-1}$ for $\mathrm{Ni}^{2+}, \mathrm{Cr}_{2} \mathrm{O}_{7}{ }^{2-}$, and $\mathrm{Co}^{2+}$, and the LOQ was $5.0 \mu \mathrm{g} \mathrm{L}^{-1} \mathrm{for} \mathrm{Hg}^{2+}$. Enrichment factors that were calculated from the ratio of the calibration curve slopes for the metal ions before and after their preconcentration by ISLD-DLLME were 64, 126, 204 and 230 for $\mathrm{Ni}^{2+}, \mathrm{Cr}_{2} \mathrm{O}_{7}{ }^{2-}$, $\mathrm{Co}^{2+}$, and $\mathrm{Hg}^{2+}$, respectively.

The proposed ISLD-DLLME was compared with the other preconcentration techniques with various chelating ligands based on DLLME, as summarized in Table 2. The ISLD-DLLME method was comparable to the other methods regarding the analytical performance in terms of sensitivity (LODs). However, ISLD-DLLME coupled to HPLC was superior to the others in respect to facility, rapidity and cost effectiveness. Furthermore, the proposed method was also preferable in regards to the eco-friendly aspect (using a less toxic solvent as the extraction solvent).

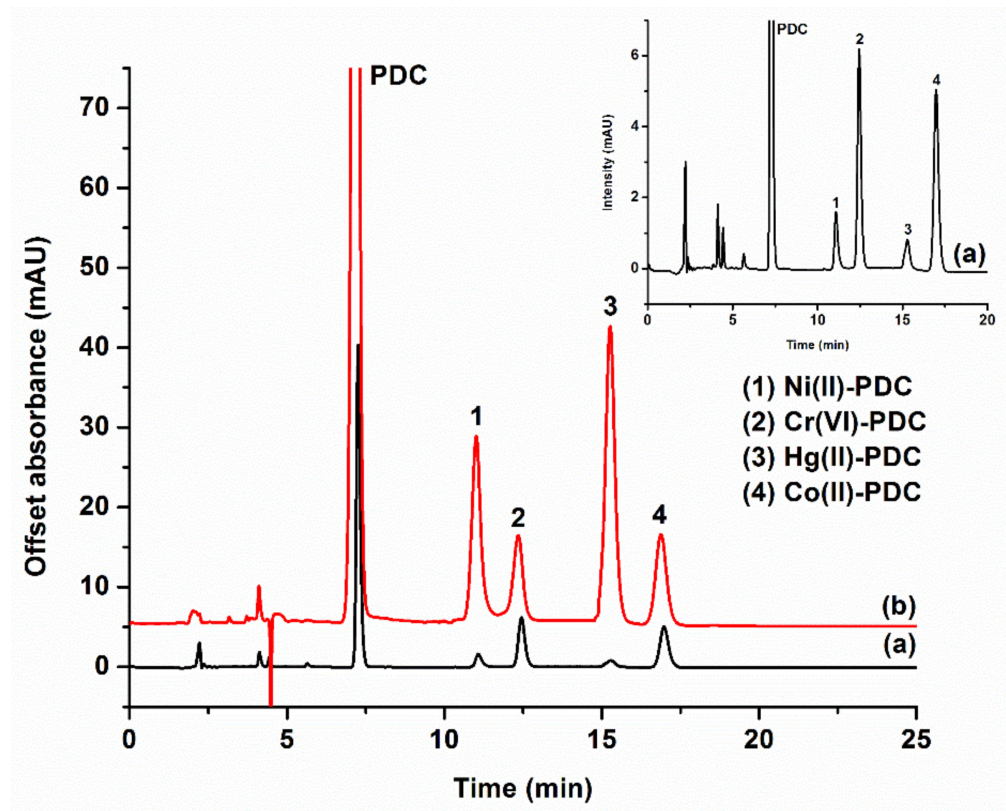

Figure 4. Chromatograms of the studied metals: (a) and (a) inset obtained from direct HPLC analysis PDC complexes of $0.5,0.5,0.5$, and $1 \mathrm{mg} \mathrm{L}^{-1}$ for $\mathrm{Ni}^{2+}, \mathrm{Co}^{2+}, \mathrm{Cr}_{2} \mathrm{O}_{7}{ }^{2-}$, and $\mathrm{Hg}^{2+}$, respectively); (b) obtained after ISLD-DLLME (PDC complexes of $0.2,0.01,0.01$, and $0.2 \mathrm{mg} \mathrm{L}^{-1}$ for $\mathrm{Ni}^{2+}, \mathrm{Co}^{2+}$, $\mathrm{Cr}_{2} \mathrm{O}_{7}{ }^{2-}$, and $\mathrm{Hg}^{2+}$, respectively). 
Table 1. Analytical performance of the proposed method (in syringe low density solvent-dispersive liquid liquid microextraction (ISLD-DLLME)) for the determination of the metal ions.

\begin{tabular}{|c|c|c|c|c|c|c|c|c|}
\hline \multirow[b]{2}{*}{ Analyte } & \multirow{2}{*}{$\begin{array}{l}\text { Linear Range } \\
\quad\left(\mu \mathrm{g} \mathrm{L}^{-1}\right)\end{array}$} & \multirow[b]{2}{*}{ Linear Equation } & \multirow[b]{2}{*}{$\mathbf{R}^{2}$} & \multirow{2}{*}{$\begin{array}{c}\text { LOD } \\
\left(\mu g L^{-1}\right)\end{array}$} & \multirow{2}{*}{$\begin{array}{c}\text { LOQ } \\
\left(\mu \mathrm{g} \mathrm{L}^{-1}\right)\end{array}$} & \multirow[b]{2}{*}{ EF } & \multicolumn{2}{|c|}{$\%$ RSD $^{*}$} \\
\hline & & & & & & & $\begin{array}{l}\text { Intra-Day } \\
\quad(n=5)\end{array}$ & $\begin{array}{c}\text { Inter-Day } \\
(\mathrm{n}=3 \times 5)\end{array}$ \\
\hline $\mathrm{Ni}^{2+}$ & $\begin{array}{c}0.05-5 \\
(5-500)^{\mathrm{a}}\end{array}$ & $\begin{array}{c}y=2.681 x+4.493 \\
(y=0.042 x-1.654)\end{array}$ & $\begin{array}{c}0.9952 \\
(0.9951)\end{array}$ & $\begin{array}{c}0.014 \\
(1.6)\end{array}$ & $\begin{array}{c}0.050 \\
(5.7)\end{array}$ & 64 & $\begin{array}{c}7.1 \\
(5.1)\end{array}$ & $\begin{array}{c}8.9 \\
(7.9)\end{array}$ \\
\hline $\mathrm{Cr}_{2} \mathrm{O}_{7}{ }^{2-}$ & $\begin{array}{c}0.05-5 \\
(10-500)\end{array}$ & $\begin{aligned} y & =19.59 x-0.626 \\
(y & =0.155 x-1.186)\end{aligned}$ & $\begin{array}{c}0.9964 \\
(0.9960)\end{array}$ & $\begin{array}{l}0.011 \\
(3.1)\end{array}$ & $\begin{array}{c}0.049 \\
(10)\end{array}$ & 126 & $\begin{array}{l}5.6 \\
(4.4)\end{array}$ & $\begin{array}{l}7.0 \\
(6.1)\end{array}$ \\
\hline $\mathrm{Hg}^{2+}$ & $\begin{array}{c}5-200 \\
(500-1000)\end{array}$ & $\begin{array}{c}y=2.301 x+17.35 \\
(y=0.010 x-3.081)\end{array}$ & $\begin{array}{c}0.9979 \\
(0.9942)\end{array}$ & $\begin{array}{c}2.0 \\
(120)\end{array}$ & $\begin{array}{c}5.0 \\
(460)\end{array}$ & 230 & $\begin{array}{l}5.8 \\
(2.8)\end{array}$ & $\begin{array}{c}8.1 \\
(4.9)\end{array}$ \\
\hline $\mathrm{Co}^{2+}$ & $\begin{array}{c}0.05-5 \\
(20-500)\end{array}$ & $\begin{array}{c}y=34.09 x+4.304 \\
(y=0.167 x-2.411)\end{array}$ & $\begin{array}{l}0.9945 \\
(0.9956)\end{array}$ & $\begin{array}{l}0.011 \\
(5.8)\end{array}$ & $\begin{array}{c}0.047 \\
(18)\end{array}$ & 204 & $\begin{array}{l}6.3 \\
(2.7)\end{array}$ & $\begin{array}{l}7.2 \\
(5.2)\end{array}$ \\
\hline
\end{tabular}

a Value of standard without preconcentration (direct HPLC analysis). * The relative standard deviation of the LOD.

Table 2. Comparison of the proposed ISLD-DLLME method with other preconcentration methods for the determination of metal ions.

\begin{tabular}{|c|c|c|c|c|c|c|c|c|c|}
\hline $\begin{array}{c}\text { Method } \\
\text { (Chelating Agent) }\end{array}$ & $\begin{array}{c}\text { Sample } \\
\text { (Metal Ions Studied) }\end{array}$ & $\begin{array}{l}\text { Extraction Solvent } \\
\text { (Dispersive Solvent) }\end{array}$ & $\begin{array}{l}\text { Extractant Volume } \\
\text { (Disperser Volume) }\end{array}$ & $\begin{array}{l}\text { Extraction } \\
\text { Time (min) }{ }^{a}\end{array}$ & $\operatorname{LOD}\left(\mu \mathrm{g} \mathrm{L}^{-1}\right)$ & EF & RSDs (\%) & $\begin{array}{l}\text { Analytical } \\
\text { Technique }\end{array}$ & Ref. \\
\hline $\begin{array}{l}\text { Solvent extraction } \\
\text { (APDC) }\end{array}$ & $\begin{array}{c}\mathrm{NR} \\
\left(\mathrm{Pb}^{2+}, \mathrm{Ni}^{2+}, \mathrm{Co}^{2+}, \mathrm{Cu}^{2+}, \mathrm{Bi}^{3+},\right. \\
\left.\mathrm{In}^{3+}\right)\end{array}$ & $\begin{array}{l}\text { Re-extraction by } \\
\text { acetonitrile }\end{array}$ & $2 \mathrm{~mL}$ & 21 & $0.023-0.21$ & NR & $\leq 9.2$ & HPLC-UV & [39] \\
\hline $\begin{array}{l}\text { UA-DLLME-SAP } \\
\text { (APDC) }\end{array}$ & $\begin{array}{c}\text { Water } \\
\left(\mathrm{Ni}^{2+}, \mathrm{Co}^{2+}, \mathrm{Cd}^{2+}, \mathrm{Cu}^{2+}, \mathrm{Pb}^{2+}\right)\end{array}$ & Cyphos IL 104 & $10 \mu \mathrm{L}$ & 66 & $0.02-0.03$ & $207-211$ & $\leq 7$ & HPLC-UV & [23] \\
\hline $\begin{array}{l}\text { UA-DLLME } \\
\text { (TOMATS) }\end{array}$ & $\begin{array}{c}\text { Tea } \\
\left(\mathrm{Cd}^{2+}, \mathrm{Co}^{2+}, \mathrm{Pb}^{2+}\right)\end{array}$ & TOMATS IL & $10 \mu \mathrm{L}$ & 17 & $2-13$ & 200 & $\leq 12$ & HPLC-UV & [45] \\
\hline $\begin{array}{c}\text { Automated DLLME } \\
\text { (2-ME) }\end{array}$ & $\begin{array}{c}\text { Water } \\
\left(\mathrm{Hg}^{2+}, \mathrm{MeHg}^{+}, \mathrm{EtHg}^{+}\right)\end{array}$ & $\begin{array}{l}{\left[\mathrm{C}_{6} \mathrm{MIM}\right]\left[\mathrm{PF}_{6}\right]} \\
\text { (acetone) }\end{array}$ & $\begin{array}{c}30 \mu \mathrm{L} \\
(800 \mu \mathrm{L})\end{array}$ & 2 & $0.0015-0.003$ & $41-47$ & $\leq 5.1$ & HPLC-CVAFS & [46] \\
\hline $\begin{array}{l}\text { Cloud point } \\
\text { extraction } \\
\text { (TAN) }\end{array}$ & $\begin{array}{c}\text { Water } \\
\left(\mathrm{Cr}^{3+}, \mathrm{Cr}^{6+}\right)\end{array}$ & $1.25 \%$ Triton X-114 & NR & 45 & $3.5-7.5$ & $40-45$ & $\leq 4.7$ & HPLC-UV & [47] \\
\hline $\begin{array}{l}\text { ISLD-DLLME } \\
\quad(\text { APDC) }\end{array}$ & $\begin{array}{c}\text { Fish, shrimp, shellfish } \\
\left(\mathrm{Ni}^{2+}, \mathrm{Cr}_{2} \mathrm{O}_{7}^{2-}, \mathrm{Co}^{2+}, \mathrm{Hg}^{2+}\right)\end{array}$ & $\begin{array}{l}\text { 1-octanol } \\
\text { (Methanol) }\end{array}$ & $\begin{array}{c}50 \mu \mathrm{L} \\
(250 \mu \mathrm{L})\end{array}$ & 1 & $0.01-2$ & $64-230$ & $\leq 8.9$ & HPLC-UV & $\begin{array}{l}\text { This } \\
\text { work }\end{array}$ \\
\hline
\end{tabular}

a Extraction time: total time in preconcentration procedures. NR: not reported. TOMATS IL: Trioctylmethylammonium thiosalicylate ionic liquid. 2-ME: 2-Mercaptoethanol. TAN: 1-(2-thiazolylazo)-2-naphthol. UA-DLLME-SAP: ultrasound-assisted dispersive liquid-liquid microextraction based on the solidification of the aqueous phase. 


\subsubsection{Interference Studies}

The foreign ions including cations that were capable of forming complexes with PDC were investigated as the interferences. The study was performed by individually spiking increasing amounts of foreign ions into the standard solution that contained a mixture of the PDC complexes of the studied metal ions (10 $\mathrm{g} \mathrm{L} \mathrm{L}^{-1}$ of each metal ions) before being subjected to ISLD-DLLME followed by HPLC. The results are expressed as the tolerance ratio, which is defined as the concentration ratio of the foreign ions that given the deviation of peak area of the analytes $\geq 5 \%$. The results are summarized in Table S1, indicating that the studied foreign ions did not significantly affect the separation and determination of the studied metal ions.

\subsubsection{Analysis of Samples}

To verify the applicability of the proposed method, freshwater fish, shrimp and shellfish samples were studied. To compensate the matrix effect, matrix match calibration curves with five difference concentrations of the metal ions standards were used for each sample. The studied metal ions were not detected in all the studied samples. The accuracy of the proposed method was then studied in terms of percentage recovery. The recovery was investigated by spiking known amounts of metal ions to each sample before the analysis by ISLD-DLLME and HPLC. The results are presented in Tables S2-S4 (supplementary data), and the obtained acceptable recoveries were in the range of $64.3 \%-114.7 \%$ (on average). Figure 5a-c depicts the typical chromatograms of the Esomus metallicus fish blank sample and the spiked sample; it can clearly be seen that the peaks of analytes were not interfered with by the matrix. Therefore, the proposed ISLD-DLLME combined with HPLC has the potential to detect metal ions in real samples. Moreover, there were no statistically significant differences between the results that were obtained by the developed method and ICP-OES at the 95\% confidence level, as evaluated by the paired t-test. The $t_{\text {critical }}$ value is 2.57 at degree of freedom 5 (from six samples), while the $t_{\text {calculated }}$ values were $0.615,0.286$ and 1.40 for $\mathrm{Ni}^{2+}, \mathrm{Cr}_{2} \mathrm{O}_{7}{ }^{2-}$, and $\mathrm{Co}^{2+}$, respectively, at the spiked concentration of $2.50 \mu \mathrm{g} \mathrm{kg}^{-1}$ and the $\mathrm{t}_{\text {calculated }}$ value of 1.24 for $\mathrm{Hg}^{2+}$ spiked at $250 \mu \mathrm{g} \mathrm{kg}^{-1}$.

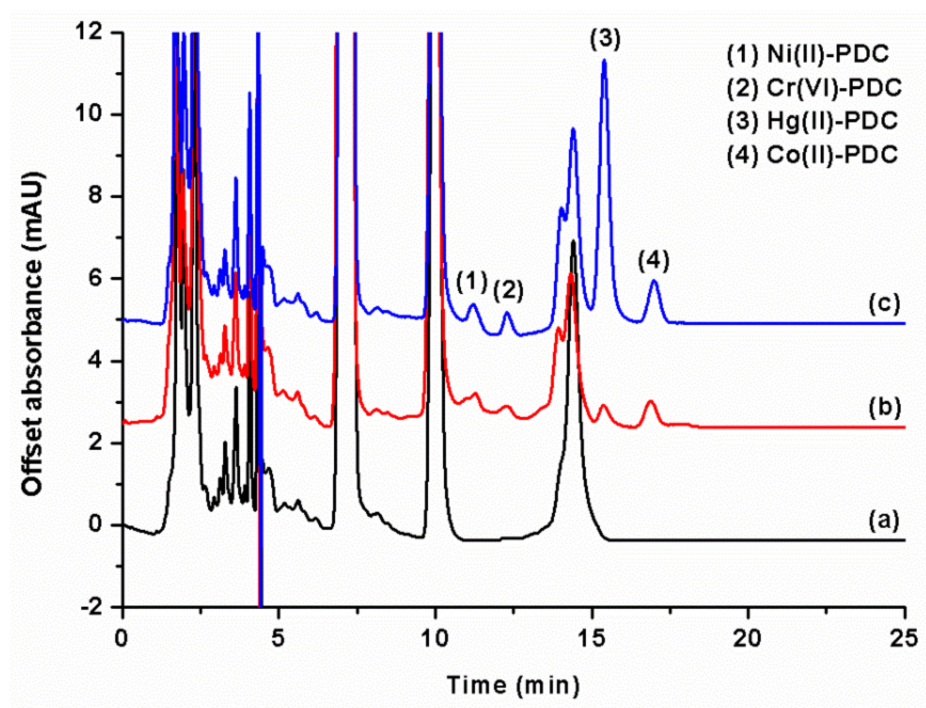

Figure 5. Chromatograms of Esomus metallicus fish. (a) Blank sample; (b) spiked sample $\left(2.5 \mu \mathrm{g} \mathrm{kg}{ }^{-1}\right.$ for $\mathrm{Ni}^{2+}, \mathrm{Cr}_{2} \mathrm{O}_{7}{ }^{2-}$, and $\mathrm{Co}^{2+}$, and $250 \mu \mathrm{g} \mathrm{kg}{ }^{-1}$ for $\left.\mathrm{Hg}^{2+}\right)$; and (c) spiked sample $\left(25 \mu \mathrm{g} \mathrm{kg}{ }^{-1}\right.$ for $\mathrm{Ni}^{2+}$, $\mathrm{Cr}_{2} \mathrm{O}_{7}{ }^{2-}$, and $\mathrm{Co}^{2+}$, and $500 \mu \mathrm{g} \mathrm{kg}{ }^{-1}$ for $\mathrm{Hg}^{2+}$ ). 


\section{Experimental}

\subsection{Chemicals and Solutions}

The standard solutions (1000 $\mathrm{mg} \mathrm{L}^{-1}$ for AAS) of $\mathrm{Ni}^{2+}, \mathrm{Hg}^{2+}$, and $\mathrm{Co}^{2+}$ were purchased from Merck (Darmstadt, Germany), Fisher Scientific (Loughborough, UK) and Carlo Erba (Val-de-Reuil, France), respectively. The stock solution (1000 $\mathrm{mg} \mathrm{L}^{-1}$ ) of $\mathrm{Cr}_{2} \mathrm{O}_{7}{ }^{2-}$ that was prepared by dissolving $\mathrm{K}_{2} \mathrm{Cr}_{2} \mathrm{O}_{7}$ (Ajax Finechem, Auckland, New Zealand) in a $0.01 \mathrm{~mol} \mathrm{~L}^{-1}$ sulfuric acid. Ammonium pyrrolidine dithiocarbamate (APDC, $\geq 98.0 \%$ ) from Sigma-Aldrich (St. Louis, MO, USA) was used as the complexing agent.

Working standard solutions of heavy metal ions were freshly prepared via the dilution of an appropriate amount of the standard stock solutions in deionized water. 1-octanol (Panreac, Barcelona, Spain), 1-dodecanol (Sigma-Aldrich, USA) and 1-undecanol (Sigma-Aldrich, USA) were investigated as the extraction solvents. Sodium chloride (Ajax Finechem, New Zealand), sodium carbonate (Ajax Finechem, New Zealand), sodium hydroxide (Carlo Erba, France), sodium sulfate (Carlo Erba, France), acetone (Carlo Erba, France), ethyl acetate (Sigma-Aldrich, USA), 65\% nitric acid (Sigma-Aldrich, USA) and 37\% hydrochloric acid (QRëc, Auckland, New Zealand) were used. Methanol and ACN (HPLC grade) were purchased from Merck (Darmstadt, Germany). Buffer solutions of $0.1 \mathrm{~mol} \mathrm{~L}^{-1}$ phosphate ( $\mathrm{pH} 3.0,5.0,7.0,9.0)$ were used. All solutions were prepared in deionized water with the resistivity of $18.2 \mathrm{M} \Omega \mathrm{cm}$ from RiOs ${ }^{\mathrm{TM}}$ Type I Simplicity 185 (Millipore, Burlington, MA, USA). Whatman no. 1 filter paper was obtained from GE Healthcare (GE Healthcare, Bangkok, Thailand), and a $0.45 \mu \mathrm{m}$ nylon membrane filter was obtained through vertical chromatography (Vertical Chromatography, Bangkok, Thailand). All glassware in these experiments were kept in $10 \%(\mathrm{v} / \mathrm{v})$ nitric acid overnight and thoroughly washed with deionized water before being used.

\subsection{Instrumentations}

The HPLC system consisted of an Agilent 1220 LC system VL, a binary pump, a manual injector with a sample loop of $10 \mu \mathrm{L}$, and an Agilent 1260 Infinity II Multiple Wavelength Detector (MWD, Agilent technologies, Santa Clara, CA, USA). Data acquirement and processing were performed by using OpenLAB CDS Chemstation software. A vortex mixer $(50 \mathrm{~Hz}$, Scientific Industries, Bohemia, NY, USA) was used to mix the solution and accelerate the phase separation. A pH meter (Model B210, ProLine, Oosterhout, The Netherlands) with a lab $\mathrm{pH}$ electrode was used for the $\mathrm{pH}$ measurements.

A Multiwave Microwave Sample Preparation System that was equipped with an 8 SXF100 rotor, and 8 XF100 vessels (Anton Paar, Graz, Austria) were used for sample preparation.

\subsection{In Syringe Low Density Solvent-Dispersive Liquid Liquid Microextraction (ISLD-DLLME)}

An aliquot of $10.00 \mathrm{~mL}$ aqueous solution containing a mixture of standard metal ions and $1 \mathrm{~mL}$ of a $0.1 \mathrm{~mol} \mathrm{~L}^{-1}$ phosphate buffer was placed in a $10 \mathrm{~mL}$-plastic syringe, and then $475 \mu \mathrm{L}$ of $1 \mathrm{mmol} \mathrm{L}^{-1}$ APDC as the chelating agent was injected into the syringe. A mixture of the extraction solvent and the disperser solvent was rapidly injected, and the syringe tip was sealed with parafilm. Afterwards, the solution was vortexed at $1800 \mathrm{~g}$-force, in which a cloudy solution was immediately observed. The parafilm on the tip of syringe was then removed. The extraction phase was moved into the tip of syringe by slowly pushing the plunger of syringe. The extraction phase was collected by a microsyringe and was diluted with $5 \mu \mathrm{L}$ of methanol before being injected into HPLC for analysis. The schematic diagram for the extraction procedure of ISLD-DLLME is illustrated in Figure 6. 


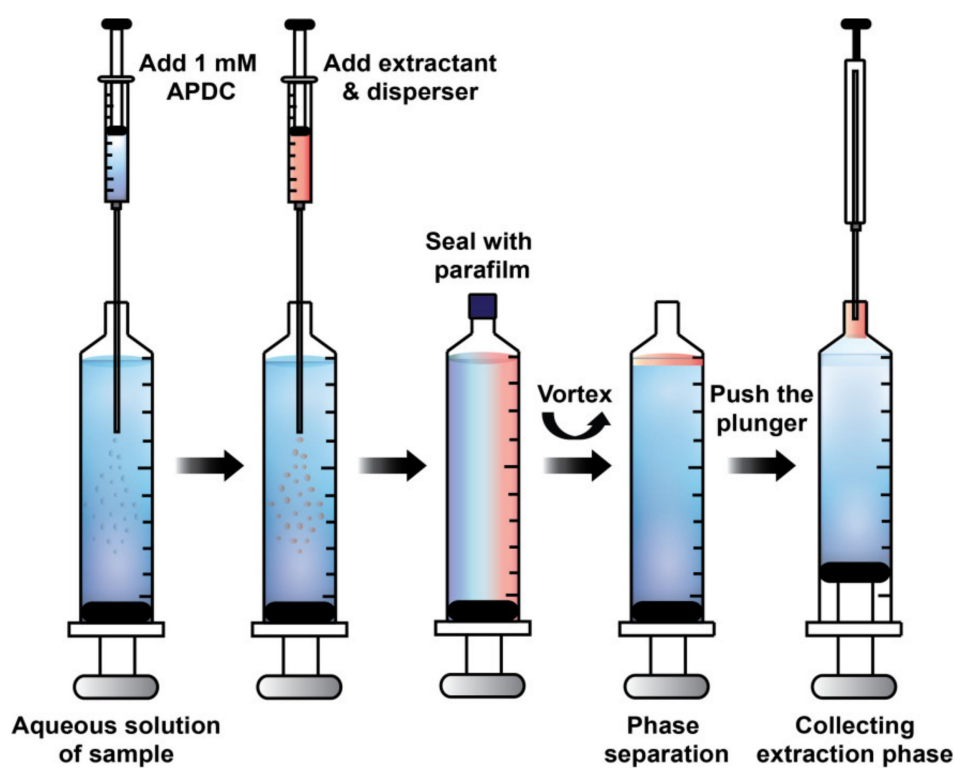

Figure 6. Schematic diagram illustrating ISLD-DLLME for the enrichment of the PDC complexes of $\mathrm{Ni}^{2+}, \mathrm{Cr}_{2} \mathrm{O}_{7}^{2-}, \mathrm{Co}^{2+}$, and $\mathrm{Hg}^{2+}$.

In order to obtain the most effective conditions, the experimental parameters that influence the extraction efficiency were optimized by investigating a single parameter at a time in the following order: $\mathrm{pH}$, type and volume of extraction solvent, type and volume of disperser solvent, extraction time, and ionic strength. The extractions were carried out in a $10 \mathrm{~mL}$-plastic syringe. The standard solution studied was $10 \mathrm{~mL}$ of aqueous solution in a mixture of $0.2,0.01,0.01$ and $0.2 \mathrm{mg} \mathrm{L}^{-1} \mathrm{of} \mathrm{Ni}^{2+}, \mathrm{Co}^{2+}$, $\mathrm{Cr}_{2} \mathrm{O}_{7}{ }^{2-}$ and $\mathrm{Hg}^{2+}$, respectively, and $1 \mathrm{mmol} \mathrm{L}^{-1}$ of PDC was used throughout. All the experiments were performed in triplicate. The extraction efficiency was evaluated through a comparison of the mean peak area $(n=3)$ that was obtained from the chromatograms.

\subsection{Liquid Chromatography}

The chromatographic separation of the metal complexes was carried out on an ACE Excel 5 C18 AR $(150 \times 4.6 \mathrm{~mm}$ i.d., $5.0 \mu \mathrm{m})$ column (ACE, Aberdeen, Scotland) with isocratic elution by using a mixture of $\mathrm{ACN}$ and a water at ratio of $70 / 30(v / v)$ at a flow rate of $1.0 \mathrm{~mL} \mathrm{~min} \mathrm{~m}^{-1}$ and detection at $254 \mathrm{~nm}$.

\subsection{Sample Preparation}

The studied samples were Oreochromis niloticus, Esomus metallicus, Macrognathus siamensis, Saccostrea commercialis, Macrobrachium lanchesteri and Litopenaeus vannamei. They were purchased from a local market in Khon Kaen, Thailand. The samples were prepared by taking thin slices of muscle tissue, cutting them into small pieces, and thoroughly chopping them. The samples were acid digested by using a microwave oven. A precise weight $(0.2 \mathrm{~g})$ of the samples was placed in a Teflon vessel. After that, $3.0 \mathrm{~mL}$ of $65 \% \mathrm{HNO}_{3}, 1.0 \mathrm{~mL}$ of $37 \% \mathrm{HCl}$, and $1.0 \mathrm{~mL}$ of $\mathrm{H}_{2} \mathrm{O}$ were added. Afterwards, the solution was filtered, and the filtrate was diluted to $25 \mathrm{~mL}$ with water. An aliquot (1 mL) of the diluted filtrate adjusted to $\mathrm{pH}$ of 5 with $5 \mathrm{~mol} \mathrm{~L}^{-1} \mathrm{NaOH}$ before subjected to ISLD-DLLME (Section 3.3) and followed by HPLC analysis (Section 3.4).

\section{Conclusions}

A simplified DLLME, namely in syringe low density solvent-dispersive liquid liquid microextraction (ISLD-DLLME) has been successfully developed for the preconcentration of the PDC complexes of $\mathrm{Ni}^{2+}, \mathrm{Cr}_{2} \mathrm{O}_{7}{ }^{2-}, \mathrm{Co}^{2+}$, and $\mathrm{Hg}^{2+}$ prior to their determination by HPLC. Besides, 
simplicity, rapidity of the method and environmentally friendly characteristics of the solvents used, ISLD-DLLME is also cost effective from the use of commercially available plastic syringe as the extraction device. The proposed method (ISLD-DLLME coupled with HPLC) offers sensitivity and selectivity for the simultaneous determination of the trace concentration of the studied metal ions. The applicability of the method was demonstrated for freshwater fish, shrimp and shellfish samples. Under the optimum conditions, the LODs based on the analysis of the studied samples were $0.50-100 \mu \mathrm{g} \mathrm{kg}^{-1}$, which are lower than DRIs and MRLs of the metal ions in fish and foods. Therefore, the proposed ISLD-DLLME method can be used as an alternative preconcentration technique for the trace analysis of metal ions.

Supplementary Materials: The following are available online, Figure S1: The effect of the $\mathrm{pH}$ on the extraction efficiency, Figure S2: The effect of the extraction time on the extraction efficiency, Table: Condition wet digestion for microwave, Table S1: Effect of interference ions on the detection of metal ions, Table S2: The determination of metal ions and recovery in Oreochromis niloticus fish and Esomus metallicus fish, Table S3: The determination of metal ions and recovery in Macrognathus siamensis fish and Macrobrachium lanchesteri shimp, Table S4: The determination of metal ions and recovery in Litopenaeus vannamei shrimp and Saccostrea commercialis shellfish, Table S5: Results of the accuracy of the extraction procedure.

Author Contributions: Conceptualization and Methodology, S.S. and S.M.; Conduction the Study, M.L.; Data Analysis, M.L., S.M. and S.S.; Manuscript Preparation, M.L.; Manuscript Revision, S.M. and S.S. All authors have read and agreed to the published version of the manuscript.

Funding: Financial supports from Materials Chemistry Research Center (MCRC) and the Center of Excellence for Innovation in Chemistry (PERCH-CIC), Office of the Higher Education Commission, Ministry of Education are gratefully acknowledged.

Conflicts of Interest: The authors declare no conflicts of interest.

\section{References}

1. Tchounwou, P.B.; Yedjou, C.G.; Patlolla, A.K.; Sutton, D.J. Heavy Metal Toxicity and the Environment. Natl. Inst. Health 2012, 101, 133-164.

2. Shrivas, K.; Dewangan, K.; Ahmed, A. Surfactant-based dispersive liquid-liquid microextraction for the determination of zinc in environmental water samples using flame atomic absorption spectrometry. Anal. Methods 2016, 8, 5519-5525. [CrossRef]

3. Sakanupongkul, A.; Sananmuang, R.; Udnan, Y.; Ampiah-Bonney, R.J.; Chaiyasith, W.C. Speciation of mercury in water and freshwater fish samples by a two-step solidified floating organic drop microextraction with electrothermal atomic absorption spectrometry. Food Chem. 2019, 277, 496-503. [CrossRef] [PubMed]

4. Mikuła, B.; Puzio, B. Determination of trace metals by ICP-OES in plant materials after preconcentration of 1,10-phenanthroline complexes on activated carbon. Talanta 2007, 71, 136-140. [CrossRef]

5. Çelik, I.; Kara, D.; Karadaş, C.; Fisher, A.; Hill, S.J. A novel ligand less-dispersive liquid-liquid microextraction method for matrix elimination and the preconcentration of rare earth elements from natural waters. Talanta 2015, 134, 476-481. [CrossRef]

6. Liao, S.; Zhu, F.; Zhao, X.; Yang, H.; Chen, X. A reusable P, N-doped carbon quantum dot fluorescent sensor for cobalt ion. Sens. Actuator B: Chem. 2018, 260, 156-164. [CrossRef]

7. Huang, Y.; Wang, S.; Wang, Z.; Wang, L.; Gao, H.; Xue, Y.; Lou, X. Task-specific ionic liquid-enabled mercury sensor for sensitive detection of total mercury in food digestion solution. Sens. Actuator B: Chem. 2019, 285, 62-67. [CrossRef]

8. Gettar, R.T.; Garavaglia, R.N.; Gautier, E.A.; Batistoni, D.A. Determination of inorganic and organic anionic arsenic species in water by ion chromatography coupled to hydride generation-inductively coupled plasma atomic emission spectrometry. J. Chromatogr. A 2000, 884, 211-221. [CrossRef]

9. Vassileva, E.; Becker, A.; Broekaert, J.A.C. Determination of arsenic and selenium species in groundwater and soil extracts by ion chromatography coupled to inductively coupled plasma mass spectrometry. Anal. Chim. Acta 2001, 441, 135-146. [CrossRef]

10. Proch, J.; Niedzielski, P. In-spray chamber hydride generation by multi-mode sample introduction system (MSIS) as an interface in the hyphenated system of high performance liquid chromatography and inductivity coupled plasma optical emission spectrometry (HPLC/HG-ICP-OES) in arsenic species determination. Talanta 2020, 208, 1-9. 
11. Bezerra, M.A.; dos Santos, W.N.L.; Lemos, V.A.; Korn, M.d.G.A.; Ferreira, S.L.C. On-line system for preconcentration and determination of metals in vegetables by inductively coupled plasma optical emission spectrometry. J. Hazard. Mater. 2007, 148, 334-339. [CrossRef] [PubMed]

12. Ozdemir, S.; Kilinc, E.; Oner, E.T. Preconcentrations and determinations of copper, nickel and lead in baby food samples employing Coprinus silvaticus immobilized multi-walled carbon nanotube as solid phase sorbent. Food Chem. 2019, 276, 174-179. [CrossRef] [PubMed]

13. Agency for Toxic Substances and Disease Registry (ATSDR). Toxicological Profile for Cobalt. Public Health Service. Available online: https:/www.atsdr.cdc.gov/toxprofiles/tp.asp?id=373\&tid=64 (accessed on 27 April 2004).

14. Guertin, J.; Jacobs, J.A.; Avakian, C.P. Overview of chromium(VI) in the environment: Background and history. In Chromium (VI) Handbook; CRC Press Taylor \& Francis Group: Boca Raton, FL, America, 2005; pp. 1-20.

15. Jarüp, L. Hazards of heavy metal contamination. Br. Med. Bull. 2003, 68, 167-182. [CrossRef] [PubMed]

16. USDA Foreign Agricultural Service, China, Peoples Republic of FAIRS Product Specific. Maximum Levels of Contaminants in Foods. Available online: https://apps.fas.usda.gov/gainfiles/200608/146208660.pdf (accessed on 12 November 2014).

17. Coulibaly, M.; Bamba, D.; Yao, N.A.; Zoro, E.G.; El Rhazi, M. Some aspects of speciation and reactivity of mercury in various matrices. Comptes. Rendus. Chim. 2016, 19, 832-840. [CrossRef]

18. World Health Organization GEMS/Food-EURO second workshop on reliable evaluation of low-level contamination of food. Available online: http://www.who.int/foodsafety/publications/chem/en/lowlevel_ may1995.pdf (accessed on 26 May 1995).

19. Ryu, K.Y.; Lee, S.Y.; Park, D.Y.; Kim, S.Y.; Kim, C. A novel colorimetric chemosensor for detection of $\mathrm{Co}^{2+}$ and $S^{2-}$ in an aqueous environment. Sens. Actuators B Chem. 2017, 242, 792-800. [CrossRef]

20. Kocúrová, L.; Balogh, I.S.; Nagy, L.; Billes, F.; Simon, A.; Andruch, V. Application of a bisindocarbocyanine reagent for dispersive liquid-liquid microextraction of silver with subsequent spectrophotometric determination. Microchem. J. 2011, 99, 514-522. [CrossRef]

21. Sajid, M. Dispersive liquid-liquid microextraction coupled with derivatization: A review of different modes, applications, and green aspects. TrAC Trends Anal. Chem. 2018, 106, 169-182. [CrossRef]

22. Chaiyamate, P.; Seebunrueng, K.; Srijaranai, S. Vortex-assisted low density solvent and surfactant based dispersive liquid-liquid microextraction for sensitive spectrophotometric determination of cobalt. RSC Adv. 2018, 8, 7243-7251. [CrossRef]

23. Werner, J. Ionic liquid ultrasound-assisted dispersive liquid-liquid microextraction based on solidification of the aqueous phase for preconcentration of heavy metals ions prior to determination by LC-UV. Talanta 2018, 182, 69-73. [CrossRef]

24. Jalbani, N.; Soylak, M. Separation-preconcentration of nickel and lead in food samples by a combination of solid-liquid-solid dispersive extraction using $\mathrm{SiO} 2$ nanoparticles, ionic liquid-based dispersive liquid-liquid micro-extraction. Talanta 2015, 131, 361-365. [CrossRef]

25. Gao, Z.; Ma, X. Speciation analysis of mercury in water samples using dispersive liquid-liquid microextraction combined with high-performance liquid chromatography. Anal. Chim. Acta 2011, 702, 50-55. [CrossRef] [PubMed]

26. Płotka-Wasylka, J.; Rutkowska, M.; Owczarek, K.; Tobiszewski, M.; Namieśnik, J. Extraction with environmentally friendly solvents. TrAC Trends Anal. Chem. 2017, 91, 12-25. [CrossRef]

27. Dadfarnia, S.; Shabani, A.M.H. Recent development in liquid phase microextraction for determination of trace level concentration of metals-A review. Anal. Chim. Acta 2010, 658, 107-119. [CrossRef] [PubMed]

28. El-Shahawi, M.S.; Al-Saidi, H.M. Dispersive liquid-liquid microextraction for chemical speciation and determination of ultra-trace concentrations of metal ions. TrAC Trends Anal. Chem. 2013, 44, 12-24. [CrossRef]

29. Seebunrueng, K.; Dejchaiwatana, C.; Santaladchaiyakit, Y.; Srijaranai, S. Development of supramolecular solvent based microextraction prior to high performance liquid chromatography for simultaneous determination of phenols in environmental water. RSC Adv. 2017, 7, 50143-50149. [CrossRef]

30. Seebunrueng, K.; Santaladchaiyakit, Y.; Srijaranai, S. Vortex-assisted low density solvent liquid-liquid microextraction and salt-induced demulsification coupled to high performance liquid chromatography for the determination of five organophosphorus pesticide residues in fruits. Talanta 2015, 132, 769-774. [CrossRef] 
31. Nakhaei, J.M.; Jamali, M.R.; Sohrabnezhad, S.; Rahnama, R. In-syringe solvent-assisted dispersive solid phase extraction followed by flame atomic absorption spectrometry for determination of nickel in water and food samples. Microchem. J. 2019, 144, 88-92. [CrossRef]

32. Xia, Y.; Cheng, M.; Guo, F.; Wang, X.; Cheng, J. In-syringe demulsified dispersive liquid-liquid microextraction and high performance liquid chromatography-mass spectrometry for the determination of trace fungicides in environmental water samples. Anal. Chim. Acta 2012, 724, 47-53. [CrossRef]

33. Ngaosi, N.; Seebunrueng, K.; Srijaranai, S. In-syringe reversed dispersive liquid-liquid microextraction coupled to high performance liquid chromatography for the determination of sulfonylurea herbicide residues in cereal samples. Anal. Methods 2016, 8, 4254-4262. [CrossRef]

34. Barreto, J.A.; Dos Santos de Assis, R.; Cassella, R.J.; Lemos, V.A. A novel strategy based on in-syringe dispersive liquid-liquid microextraction for the determination of nickel in chocolate samples. Talanta 2019, 193, 23-28. [CrossRef]

35. Dilli, S.; Tong, P. Liquid chromatography of metal chelates: Chromatographic studies of homologous dialkyldithiocarbamates. Anal. Chim. Acta 1999, 395, 101-112. [CrossRef]

36. Den Boeff, G.; Poppa, H. Differential spectrophotometry of nickel as its pyridine-2,6-dicarboxylic acid complex. Talanta 1968, 15, 1058-1060. [CrossRef]

37. Peng, B.; Shen, Y.; Gao, Z.; Zhou, M.; Ma, Y.; Zhao, S. Determination of total iron in water and foods by dispersive liquid-liquid microextraction coupled with microvolume UV-vis spectrophotometry. Food Chem. 2015, 176, 288-293. [CrossRef] [PubMed]

38. Butwong, N.; Burakham, R.; Srijaranai, S. Use of surfactant as mobile phase additive in LC for simultaneous determination of metal-pyrrolidine dithiocarbamate chelates. Chromatographia 2010, 71, 639-645. [CrossRef]

39. Shijo, Y.; Takada, K.; Uehara, N. Determination of metal ions by high-performance liquid chromatographic separation of their pyrrolidine dithiocarbamate complexes after solvent extraction. Anal. Sci. 1993, 9, 315-317. [CrossRef]

40. AOAC Official Method 973.35. Lead in Evaporated Milk. Atomic Absorption Spectrophotometric Method. Available online: http://www.wdfxw.net/doc11928282.htm (accessed on 16 June 2017).

41. Liška, O.; Lehotay, J.; Brandšteterová, E. Liquid chromatography of metal complexes of N-disubstituted dithiocarbanic acids. J. Chromatogr. 1979, 172, 384-387. [CrossRef]

42. Bone, K.M.; Hibbert, W.D. Solvent extraction with ammonium pyrrolidinedithiocarbamate and 2,6-dimethyl4-heptanone for the determination of trace metals in effluents and natural waters. Anal. Chim. Acta 1979, 107, 219-229. [CrossRef]

43. Rezaee, M.; Assadi, Y.; Milani Hosseini, M.-R.; Aghaee, E.; Ahmadi, F.; Berijani, S. Determination of organic compounds in water using dispersive liquid-liquid microextraction. J. Chromatogr. A 2006, 1116, 1-9. [CrossRef]

44. Somsubsin, S.; Seebunrueng, K.; Boonchiangma, S.; Srijaranai, S. A simple solvent based microextraction for high performance liquid chromatographic analysis of aflatoxins in rice samples. Talanta 2018, 176, 172-177. [CrossRef]

45. Werner, J. Determination of metal ions in tea samples using task-specific ionic liquid-based ultrasound-assisted dispersive liquid-liquid microextraction coupled to liquid chromatography with ultraviolet detection: Liquid Chromatography. J. Sep. Sci. 2016, 39, 1411-1417. [CrossRef]

46. Liu, Y.-M.; Zhang, F.-P.; Jiao, B.-Y.; Rao, J.-Y.; Leng, G. Automated dispersive liquid-liquid microextraction coupled to high performance liquid chromatography-cold vapour atomic fluorescence spectroscopy for the determination of mercury species in natural water samples. J. Chromatogr. A 2017, 1493, 1-9. [CrossRef] [PubMed]

47. Wang, L.-L.; Wang, J.-Q.; Zheng, Z.-X.; Xiao, P. Cloud point extraction combined with high-performance liquid chromatography for speciation of chromium(III) and chromium(VI) in environmental sediment samples. J. Hazard. Mater. 2010, 177, 114-118. [CrossRef] [PubMed]

Sample Availability: Samples of the compounds are not from the authors.

(C) 2020 by the authors. Licensee MDPI, Basel, Switzerland. This article is an open access article distributed under the terms and conditions of the Creative Commons Attribution (CC BY) license (http://creativecommons.org/licenses/by/4.0/). 